\title{
Preoperative transcatheter occlusion of bronchopulmonary collateral artery reduces reperfusion pulmonary edema and improves early hemodynamic function after pulmonary thromboendarterectomy
}

\author{
Hui-Li Gan, MD, ${ }^{\mathrm{a}}$ Jian-Qun Zhang, MD, ${ }^{\mathrm{a}}$ Jian-Chao Sun, MD, ${ }^{\mathrm{a}}$ Lei Feng, MD, ${ }^{\mathrm{a}}$ Xiao-Yong Huang, MD, \\ Jia-Kai Lu, MD, ${ }^{c}$ and Xiu-Hua Dong, $\mathrm{MD}^{\mathrm{c}}$
}

\begin{abstract}
Objective: The present study assessed the effectiveness of preoperative transcatheter occlusion of the bronchopulmonary collateral artery (PTOBPCA) in reducing reperfusion pulmonary edema after pulmonary thromboendarterectomy (PEA).
\end{abstract}

\begin{abstract}
Methods: The data from 155 patients with chronic thromboembolic pulmonary hypertension at Anzhen Hospital, treated from January 2007 to August 2013, with PEA were retrospectively reviewed. The patients were classified into a control (group $\mathrm{A}, \mathrm{n}=87$ ) and treated (group $\mathrm{B}$, underwent PTOBPCA, $\mathrm{n}=68$ ) group. The reperfusion pulmonary edema incidence, mechanical ventilation and intensive care unit hospitalization duration, and hemodynamic function were compared between the 2 groups.
\end{abstract}

\begin{abstract}
Results: Of the 87 patients in group A, 5 died in-hospital (5.7\% mortality); no patient in group B died ( $0 \%$ mortality; $P=.035)$. In group A, 9 patients $(10.3 \%)$ required extracorporeal membrane oxygenation (ECMO) after PEA; 1 patient $(1.5 \%)$ in group B required ECMO (chi-square test, $P=.026, \chi^{2}=4.980$ ). Group B had shorter intubation and intensive care unit hospitalization times, lower mean pulmonary artery pressures and pulmonary vascular resistance, higher partial pressures of oxygen in arterial blood and oxygen saturation, and decreased medical expenditure compared with group A. During a mean $37.1 \pm 21.4$ months of follow-up, 3 patients in group A and 2 in group B died; however, the difference in the actuarial survival at 3 years postoperatively between the 2 groups was not statistically significant.
\end{abstract}

Conclusions: PTOBPCA can reduce the incidence of reperfusion pulmonary edema, shorten intensive care unit hospitalization and intubation duration, improve early hemodynamic function, and reduce ECMO usage after PEA. (J Thorac Cardiovasc Surg 2014;148:3014-9)

Chronic thromboembolic pulmonary hypertension $(\mathrm{CTEPH})$ is a progressive disease characterized by chronic thromboemboli accumulation within the pulmonary arteries, leading to severe pulmonary hypertension. Pulmonary thromboendarterectomy (PEA) of the major, lobar, and segmental pulmonary arteries is the primary therapy for affected patients and can be curative in select patients. PEA has emerged as the treatment of choice for $\mathrm{CTEPH}^{1}$; however, reperfusion pulmonary edema (RPE) remains a

From the Departments of Cardiac Surgery, ${ }^{\mathrm{a}}$ Image Diagnosing, ${ }^{\mathrm{b}}$ and Anesthesiology, ${ }^{\mathrm{c}}$ Beijing Anzhen Hospital, Capital Medical University, and Beijing Institute of Heart, Lung and Blood Vessel Disease, Beijing, China.

This project was supported by the China Nature Science Foundation Committee (grant 81070041), the Beijing Health System Special Foundation for Building High-level Health Personnel (grant 2013-2-002), and the Beijing Science and Technology Project (grant Z121107001012067). The funders had no role in the study design, data collection and analysis, decision to publish, or preparation of the manuscript.

Disclosures: Authors have nothing to disclose with regard to commercial support. Received for publication March 12, 2014; revisions received April 23, 2014; accepted for publication May 9, 2014; available ahead of print June 11, 2014.

Address for reprints: Hui-Li Gan, MD, Department of Cardiac Surgery, Beijing Anzhen Hospital, Capital Medical University, and Beijing Institute of Heart, Lung and Blood Vessel Disease, Beijing 100029, China (E-mail: ganhuili@126.com).

0022-5223/\$36.00

Copyright (c) 2014 by The American Association for Thoracic Surgery

http://dx.doi.org/10.1016/j.jtcvs.2014.05.024 major risk factor and complication during and immediately after PEA and has been associated with adverse short-term and long-term consequences. ${ }^{2}$ The in-hospital mortality has been as high as $15 \%$ after PEA in some reports, with the principal causes being RPE and persistent pulmonary hypertension.

Bronchopulmonary arterial dilatation is a wellrecognized feature in patients with $\mathrm{CTEPH}^{4}{ }^{4}$ In our practice, we have found that the patients undergoing preoperative transcatheter occlusion of the bronchopulmonary collateral artery (BPCA) tended to have a more uneventful recovery than those who had not undergone the procedure. Therefore, we hypothesized that preoperative transcatheter occlusion of the BPCA (PTOBPCA) might reduce the incidence of RPE and improve early hemodynamic function after PEA. To test this hypothesis, we retrospectively evaluated patients with CTEPH who had undergone PTOBPCA and those who had not and measured the rate of postoperative complications, such as RPE, mechanical ventilation duration, morbidity, and mortality.

\section{METHODS}

The local ethics committee at Beijing Anzhen Hospital and Beijing Institute of Heart, Lung, and Blood Vessel Diseases approved the use of 


\section{Abbreviations and Acronyms \\ BPCA = bronchopulmonary collateral artery \\ $\mathrm{CTEPH}=$ chronic thromboembolic pulmonary hypertension \\ $\mathrm{ECMO}=$ extracorporeal membrane oxygenation \\ ICU = intensive care unit \\ OPS = occluded pulmonary segment \\ PEA = pulmonary thromboendarterectomy \\ RPE $=$ reperfusion pulmonary edema}

clinical data for the present study. Each participant provided written informed consent to undergo the surgical or transcatheter procedure and the use of their data for clinical research.

\section{Patients}

A total of 155 consecutive PEA procedures performed on patients diagnosed with CTEPH at the Beijing Anzhen Hospital, China, from January 2007 to August 2013, were evaluated. Patient age at the initial admission ranged from 17 to 75 years (mean, $45.7 \pm 16.2$ ). Of the 155 patients, 78 were categorized into World Health Organization functional class IV and 79 into World Health Organization functional class III. Additionally, 93 patients had a history of deep vein thrombosis in the lower extremities. Preoperatively, the enlarged BPCAs were not occluded in 87 patients (group A) and were occluded in 68 patients (group B).

Pulmonary angiography, pulmonary artery computed tomographic angiography or pulmonary artery magnetic resonance imaging, isotope ventilation/perfusion scintigraphy, and echocardiography were used to characterize the pathophysiologic features of CTEPH and to calculate the occluded pulmonary segment (OPS). In $95 \%$ of the patients, pulmonary artery computed tomographic angiography and isotope ventilation/perfusion scintigraphy were performed within 7 days before PEA.

Right-sided heart catheterization was performed preoperatively to assess the hemodynamic status in all 155 patients. The right atrial pressure, pulmonary artery pressure, and pulmonary capillary wedge pressure were measured using standard clinical methods, and the cardiac output was measured using the Fick procedure. Additionally, the patients underwent right-sided heart catheterization 0 and 72 hours after PEA using a SwanGanz catheter while hospitalized in the intensive care unit (ICU).

From the imaging findings, physical examination results, and pathologic assessment of the CTEPH surgical specimen, 113 patients were classified as having the proximal type and 42 as having the distal type of CTEPH. The patient demographics and risk factors for both groups are summarized in Table 1. The CTEPH lesion classification, pulmonary vascular resistance, pulmonary to systemic systolic artery pressure ratio, mean pulmonary artery pressure, partial pressure of oxygen in arterial blood, and oxygen saturation were distributed equally between the 2 groups.

A total of 216 patients received a surgical consultation, and 155 underwent surgical therapy. The patients were selected for PTOBPCA if they had a history of, or ongoing, hemoptysis symptoms.

\section{Therapeutic Regimen}

At 3 to 7 days before undergoing PEA, group B underwent transcatheter occlusion of the enlarged BPCA during the preoperative right-sided heart catheterizations, with the patient under local anesthesia. The normal bronchial artery and enlarged BPCA were identified using thoracic aortography, subclavian arteriography, and selective bronchopulmonary arteriography. The normal bronchial arteries were left untreated, and the enlarged BPCA (diameter $\geq 1.5 \mathrm{~mm}$ ) and the associated bronchopulmonary collateral vasculature were occluded by transcatheter coil placement. Complete vascular occlusion of the target vessel was assessed using angiography at procedure completion. Embolization of the enlarged BPCA was uneventful in all 68 patients. A mean of $1.9 \pm 0.7$ BPCAs were occluded using a mean of $2.6 \pm 1.2$ coils.

All 155 patients with CTEPH underwent standard PEA under general anesthesia with cardiopulmonary bypass and deep hypothermia circulatory arrest. PEA was performed through a median sternotomy, similar to techniques established by Jamieson and Kapelanski. ${ }^{5}$ The mean cardiopulmonary bypass duration was $232.6 \pm 35.2$ minutes, the mean clamping duration was $93.2 \pm 23.2$ minutes, and the mean circulatory arrest duration was $35.7 \pm 12.6$ minutes.

All surviving patients in both groups received lifelong warfarin postoperatively, and the international normalized ratio was maintained within a range of 2.0 to 3.0. Select patients with residual pulmonary hypertension received pulmonary vasodilator therapy, including prostanoids, endothelin receptor antagonists, phosphodiesterase-5 inhibitors, or a combination of therapies.

\section{Follow-up}

Valid and complete follow-up information was obtained for 148 of the 150 surgical survivors $(98.7 \%)$ every 3 months and yearly. The World Health Organization functional class and 6-minute walk test, transthoracic echocardiography, electrocardiography, chest radiography, and pulmonary artery computed tomographic angiography findings were recorded. The long-term clinical outcome was assessed through July 2013.

\section{Statistical Analysis}

All statistical analyses were performed using the Statistical Package for Social Sciences, version 17.0 (SPSS, Inc, Chicago, Ill). Summary statistics for all continuous variables are presented as the mean \pm standard deviation. Categorical data were summarized as frequencies and percentages. Cumulative event rates, such as actuarial survival, were estimated using the Kaplan-Meier method. Differences between the 2 groups were analyzed using the chi-square test, Fisher's exact test, $t$ test, or log-rank test, as appropriate.

\section{RESULTS \\ Early Outcomes}

The classification and frequency of graded RPE are listed in Table 2. Of the 87 patients in group A, $9(10.3 \%)$ had the most severe form, grade $5 \mathrm{RPE}$, and required life-sustaining extracorporeal membrane oxygenation (ECMO) therapy. Of the 68 patients in group B, $1(1.5 \%)$ had grade $5 \mathrm{RPE}$ and also required life-sustaining ECMO therapy (chi-square test, $P=.026, \chi^{2}=4.980$ ).

During the early postoperative period, 5 patients in group A died in-hospital (5.75\%). None of the 68 patients in group $\mathrm{B}$ died $(0 \%$; Fisher's exact test, $P=.068)$. The 5 early deaths in group A were attributed to grade 5 RPE, with or without persistent pulmonary artery hypertension and right-side heart failure (Table 3). The 2 groups were also compared by intubation and ICU duration, mean pulmonary artery pressure, pulmonary vascular resistance, partial pressure of oxygen in arterial blood, oxygen saturation, and medical expenditure. The findings are summarized in Table 4.

\section{Long-Term Outcomes}

The 150 surgical survivors were followed up for 1 to 80 months (mean, $37.1 \pm 21.4$ ). The cumulative follow-up 
TABLE 1. Patient demographics and risk factors in groups $A$ and $B$

\begin{tabular}{|c|c|c|c|}
\hline Variable & $\begin{array}{l}\text { Group A } \\
(\mathbf{n}=\mathbf{8 7})\end{array}$ & $\begin{array}{l}\text { Group B } \\
(\mathbf{n}=68)\end{array}$ & $\begin{array}{l}P \text { value } \\
\left(t \text { or } \chi^{2}\right)\end{array}$ \\
\hline Male gender (n) & $54(62.1)$ & $39(57.4)$ & $.668(0.184)$ \\
\hline Age (y) & $46.7 \pm 13.5$ & $47.8 \pm 12.8$ & $.607(0.515$ \\
\hline Disease course (y) & $3.6 \pm 2.8$ & $3.7 \pm 2.5$ & $.818(0.231)$ \\
\hline WHO functional class & & & $.785(0.074)$ \\
\hline III & $43(49.4)$ & $36(52.9)$ & \\
\hline IV & $44(50.6)$ & $32(47.1)$ & \\
\hline $\mathrm{PaO}_{2}(\mathrm{~mm} \mathrm{Hg})$ on room air & $66.3 \pm 8.4$ & $64.3 \pm 6.3$ & $.104(1.636$ \\
\hline $\mathrm{SaO}_{2}(\%)$ on room air & $87.2 \pm 3.7$ & $86.3 \pm 3.8$ & $.140(1.485$ \\
\hline $\mathrm{PaO}_{2} / \mathrm{FiO}_{2}$ ratio & $262 \pm 38$ & $270 \pm 32$ & $.166(1.392$ \\
\hline sPAP (mm Hg) & $96.8 \pm 26.4$ & $93.5 \pm 22.5$ & $.412(0.823$ \\
\hline PVR (dynes/s/cm ${ }^{-5}$ ) & $878 \pm 426$ & $851 \pm 381$ & $.682(0.410$ \\
\hline $\mathrm{sPAP} \geq 100 \mathrm{~mm} \mathrm{Hg}(\%)$ & $45(51.7)$ & $36(52.9)$ & $.880(0.023$ \\
\hline sPAP/sBP ratio & $0.86 \pm 0.16$ & $0.89 \pm 0.14$ & $.223(1.223$ \\
\hline mPAP $(\mathrm{mm} \mathrm{Hg})$ & $68.4 \pm 12.7$ & $67.7 \pm 13.5$ & $.741(0.331)$ \\
\hline $\begin{array}{l}\text { Ventilation/perfusion scan } \\
\text { (defect segment, OPS) }\end{array}$ & $12.7 \pm 2.8$ & $12.1 \pm 2.5$ & $.168(1.387$ \\
\hline CTEPH classification & & & $.736(0.114$ \\
\hline Proximal type & 62 & 51 & \\
\hline Distal type & 25 & 17 & \\
\hline
\end{tabular}

Data presented as $\mathrm{n}(\%)$ or mean \pm standard deviation. WHO, World Health Organization; $\mathrm{PaO}_{2}$, partial pressure of oxygen in arterial blood; $\mathrm{SaO}_{2}$, oxygen saturation; $\mathrm{PaO}_{2} / \mathrm{FiO}_{2}$ ratio, ratio of arterial oxygen tension to fraction of inspired oxygen; $S P A P$, systolic pulmonary artery pressure; $P V R$, pulmonary vascular resistance; $s P A P / s B P$, pulmonary to systemic systolic artery pressure ratio; $m P A P$, mean pulmonary artery pressure; OPS, occluded pulmonary segment; $C T E P H$, chronic thromboembolic pulmonary hypertension.

period was 412.8 patient-years. During this period, 3 patients in group A died, at 11 months, 4 years, and 5 years postoperatively, of persistent pulmonary artery hypertension and right-sided heart failure. Two patients in group B died 3 and 6 years after the procedure. From the KaplanMeier actuarial survival analysis, the difference in actuarial survival at 3 years postoperatively between groups A and B was not statistically significant $(92.9 \% \pm 2.8 \%$ vs $97.2 \%$ $\pm 2.7 \%, \log$-rank test, $\left.\chi^{2}=2.189, P=.139\right)$. The ventilation/perfusion scintigraphy studies performed 3 months after PEA showed that the OPS had decreased from $12.7 \pm 2.8$ preoperatively to $2.6 \pm 0.7$ defect segments postoperatively in the 82 group A survivors $(t=31.738, P=.000)$. In the 68 group $\mathrm{B}$ survivors, the ventilation/perfusion scintigraphy studies revealed that the OPS had decreased from $12.1 \pm$ 2.5 preoperatively to $2.7 \pm 0.9$ defect segments postoperatively ( $t=28.981, P=.000)$. However, the difference in residual OPS between the 2 groups was not statistically significant $(t=0.763, P=.447)$.

\section{DISCUSSION}

Although PEA has been the treatment of choice for CTEPH and has the potential to cure the disease, ${ }^{6}$ it has remained a rare or uncommon procedure, mainly because postoperative RPE has often led to severe mortality and morbidity. The PEA mortality has ranged from $5 \%$ to
$8.7 \%$ at experienced medical centers ${ }^{7,8}$ and has been as great as $10 \%$ to $20 \%$ at less experienced centers, ${ }^{9}$ with RPE the single most implicated cause.

RPE will occur in $10 \%$ to $60 \%$ of patients, depending on the clinical definition, ${ }^{10,11}$ and patients can experience deteriorated oxygenation and carbon dioxide clearance despite high levels of inspiratory oxygen, high peak inspiratory pressures, and high positive end-expiratory pressures. RPE is a high permeability edema occurring in endarterectomized and reperfused regions. ${ }^{12}$ At its most severe, RPE can cause severe alveolar hemorrhage, with profound hypoxemia and high mortality. ${ }^{13}$ Although the incidence of this syndrome has gradually decreased, potentially $3 \%$ to $6 \%$ of patients with severe cases will require temporary support with ECMO according to a recent series. ${ }^{14}$

Post-PEA RPE can have a highly variable presentation, from minor radiopacities on the chest radiograph to the most severe form requiring life-sustaining ECMO. ${ }^{15}$ To date, no practical grading or reporting system is available for post-PEA RPE. In a study of percutaneous transluminal pulmonary angioplasty by Inami and colleagues, ${ }^{16} \mathrm{RPE}$ was graded into 5 groups according to the severity; however, the RPE that develops after PEA has been far more severe than the lesions that have developed after percutaneous transluminal pulmonary angioplasty. Therefore, their grading system is not directly applicable to the present study. Instead, this RPE grading system was revised into a new formulation (Table 2). Of the 155 patients in the present series, 133 $(85.8 \%)$ were considered to have grades 2 to 4 , clearly indicating RPE occurrence, and $10(6.45 \%)$ were considered to have grade 5, the most severe form of RPE, and required ECMO and/or extended ventilatory support ( $>7$ days).

The exact cause and pathogenesis of RPE, whether secondary to the thromboendarterectomy itself, as suggested by Levinson and colleagues, ${ }^{12}$ or to reperfusion injury of the ischemic pulmonary endothelium, ${ }^{17}$ remains under investigation. In previous studies of isolated lungs and animal models, postischemia reperfusion was associated with increased microvascular lung permeability ${ }^{18}$ and pulmonary sequestration of activated polymorphonuclear neutrophils. ${ }^{19}$ Similarly, Fadel and colleagues ${ }^{20}$ surmised that the acute high-permeability pulmonary edema that develops after thromboendarterectomy results from an acute inflammatory response to the ischemia and reperfusion. In contrast to Levinson and colleagues, ${ }^{12}$ Fadel and colleagues ${ }^{20}$ reported that it is neither induced nor aggravated by the thromboendarterectomy itself. The pulmonary arterial intima might be disrupted during endarterectomy, leading to surgical endothelial injury, activation of the complement, coagulation, and kinin systems, and concomitant changes in endothelial permeability. ${ }^{12,21}$ Lung reperfusion is followed by a dramatic transient increase in endothelial cell apoptosis, which might trigger endothelial 
TABLE 2. Classification and frequency of graded RPE in surgical CTEPH patients

\begin{tabular}{|c|c|c|c|}
\hline Grade & RPE definition & Group A $(n=87)$ & Group B $(n=68)$ \\
\hline 1 & $\begin{array}{l}\text { No significant recognition of RPE on chest radiograph, ventilation without } \\
\text { needing PEEP to maintain arterial saturation at optimum level, and } \\
\text { extubated within } 24 \mathrm{~h} \text { after procedure }\end{array}$ & 6 & 16 \\
\hline 2 & $\begin{array}{l}\text { Mild or small RPE on chest radiograph, ventilation needing PEEP to } \\
\text { maintain arterial saturation at optimum level, and extubated within } 72 \mathrm{~h} \\
\text { after procedure }\end{array}$ & 28 & 18 \\
\hline 3 & $\begin{array}{l}\text { Moderate RPE on chest radiograph, ventilation needing PEEP to maintain } \\
\text { arterial saturation at optimum level, and extubated within } 120 \mathrm{~h} \text { after } \\
\text { procedure }\end{array}$ & 26 & 26 \\
\hline 4 & $\begin{array}{l}\text { Severe RPE on chest radiograph, ventilation needing PEEP to maintain } \\
\text { arterial saturation at optimum level, and extubated within } 148 \mathrm{~h} \text { after } \\
\text { procedure }\end{array}$ & 16 & 7 \\
\hline 5 & $\begin{array}{l}\text { Extremely severe RPE on chest radiograph such that artificial ventilation } \\
\text { and PEEP cannot maintain arterial saturation at optimum level, and } \\
\text { ECMO should be installed during or after the procedure, or the ventilation } \\
\text { duration exceeded } 148 \mathrm{~h} \text { and tracheotomy performed }\end{array}$ & 9 & 1 \\
\hline
\end{tabular}

Data presented as number of patients. $P=.005\left(\chi^{2}=14.9\right) . R P E$, Reperfusion pulmonary edema; $P E E P$, positive end-expiratory pressure; $E C M O$, extracorporeal membrane oxygenation.

dysfunction after PEA. Acute lung ischemia and reperfusion induced apoptosis in $>30 \%$ of parenchymal lung cells in human patients and animal models after lung transplantation. ${ }^{22}$ Thus, increased apoptosis might contribute substantially to the development of RPE and persistent pulmonary hypertension. Antiapoptotic agents could hold considerable potential for preventing postoperative complications. ${ }^{23}$

BPCAs develop in patients with CTEPH to perfuse the patent vasculature distal to the embolic obstruction. ${ }^{24}$ Luxuriant perfusion in these vessel structures after PEA could be associated with RPE. ${ }^{12}$ Potentially, the large blood volume redirected to previously occluded pulmonary capillary beds postoperatively could be the catalyst for this reperfusion phenomenon after pulmonary endarterectomy. ${ }^{25}$

Treatment of RPE has primarily been supportive. In most cases, therapy comprising mechanical ventilation, diuretics, and avoidance of hypercarbia and supranormal inspired oxygen concentrations will allow full lung recovery. ${ }^{26}$ Most patients will respond well to these aggressive measures. ${ }^{27}$ Several strategies have been attempted to reduce the incidence of RPE. Mares and colleagues ${ }^{28}$ proved in a clinical trial that avoiding positive inotropic catecholamines and vasodilators and using nonaggressive mechanical ventilation (low tidal volume and low peak inspiratory pressure) were associated with a low incidence of RPE and right-side heart failure after PEA. In the more severe cases, neutrophil adhesion inhibitors, high-dose corticosteroids,${ }^{29}$ inhaled nitric oxide, ${ }^{30}$ and aerosolized iloprost ${ }^{31}$ have been administered to limit RPE, with varying success. However, a very small number of PEA patients will develop life-threatening RPE postoperatively despite a good initial hemodynamic outcome. For such patients, ECMO might be the only effective therapy. ${ }^{14,27}$ In the present case series, 10 patients
$(6.45 \%)$ with grade 5 RPE had difficulty weaning from extracorporeal circulation and were immediately implanted with ECMO devices to allow survival.

We have surmised that the BPCA might be among the primary triggers for RPE after PEA. Pulmonary arterial obstructions with thromboembolic pulmonary hypertension are patchy and will largely spare the small pulmonary arteries and arterioles. ${ }^{32}$ This will allows a pressure gradient to develop between the systemic bronchial circulation and the pulmonary circulation distal to the proximal pulmonary arterial obstruction, encouraging BPCA growth. Subsequently, all patients with thromboembolic pulmonary hypertension also had dilated bronchial arteries and numerous bronchopulmonary collaterals. The BPCAs serve the pulmonary arterial branches downstream of the occluded site. Endrys and colleagues ${ }^{4}$ reported that all patients with CTEPH had significant BPCA blood flow, approximately $30 \%$ of the systemic blood flow. It has been speculated that alleviating disease in the small subsegmental pulmonary vessels, rather than the main or lobar vessels, might, in some patients, trigger a vascular leak-like syndrome that causes a severe reperfusion response. This response might reflect increased flow through new small areas of open vessels that leads to a significant ventilation-perfusion mismatch. ${ }^{33}$

After the embolized pulmonary arteries have been opened by endarterectomy, the affected lung will experience dual arterial perfusion, which will overwhelm its endothelial endurance, increase permeability, and, ultimately, trigger RPE. PTOBPCA avoids this dual arterial perfusion insult after PEA, preventing or alleviating the occurrence of RPE. We were intrigued by this practice and have adopted PTOBPCA in select PEA procedures, especially in patients with symptoms or a history of hemoptysis. During 
TABLE 3. Etiology of early and late death after PEA in both groups

\begin{tabular}{|c|c|c|c|}
\hline Pt. no. & $\begin{array}{c}\text { Postoperative } \\
\text { interval }\end{array}$ & Group & Comment \\
\hline \multicolumn{4}{|c|}{ Early death (before postoperative discharge) } \\
\hline 1 & $7 \mathrm{~d}$ & A & $\begin{array}{l}\text { Grade } 5 \text { RPE, persistent } \\
\text { pulmonary hypertension, } \\
\text { and right-sided heart failure }\end{array}$ \\
\hline 2 & $15 \mathrm{~d}$ & A & $\begin{array}{l}\text { Grade } 5 \text { RPE, persistent } \\
\text { pulmonary hypertension, } \\
\text { and right-sided heart failure }\end{array}$ \\
\hline 3 & $5 \mathrm{~d}$ & A & Grade 5 RPE \\
\hline 4 & $8 \mathrm{~d}$ & A & $\begin{array}{l}\text { Grade } 5 \text { RPE, persistent } \\
\text { pulmonary hypertension, } \\
\text { and right-sided heart failure }\end{array}$ \\
\hline 5 & $9 \mathrm{~d}$ & A & Grade 5 RPE \\
\hline \multicolumn{4}{|c|}{ Late death (after postoperative discharge) } \\
\hline 6 & $11 \mathrm{mo}$ & A & $\begin{array}{l}\text { Persistent pulmonary } \\
\text { hypertension and } \\
\text { right-sided heart failure }\end{array}$ \\
\hline 7 & $3 \mathrm{y}$ & B & Copious hemoptysis \\
\hline 8 & $4 \mathrm{y}$ & A & $\begin{array}{l}\text { Persistent pulmonary } \\
\text { hypertension and } \\
\text { right-sided heart failure }\end{array}$ \\
\hline 9 & $5 \mathrm{y}$ & $\mathrm{A}$ & $\begin{array}{l}\text { Persistent pulmonary } \\
\text { hypertension and } \\
\text { right-sided heart failure }\end{array}$ \\
\hline 10 & $6 y$ & B & $\begin{array}{l}\text { Persistent pulmonary } \\
\text { hypertension and } \\
\text { right-sided heart failure }\end{array}$ \\
\hline
\end{tabular}

Pt. no., Patient number; RPE, reperfusion pulmonary edema.

PTOBPCA, the normal bronchial arteries remain untouched, eliminating any risk of new pulmonary infarctions after BPCA embolization. Thus, no patients developed new hemoptysis symptoms after PTOBPCA in our series. This is the first report describing PTOBPCA before PEA. We believe it is worthwhile to compare the PEA procedures with and without the PTOBPCA strategy.

Bronchopulmonary arterial rupture can cause severe and sometimes lethal hemoptysis. Reesink and colleagues ${ }^{34}$ reported that 5 of 79 patients with CTEPH $(6 \%)$ in a case series had had moderate to severe hemoptysis requiring medical intervention. Because most patients with CTEPH will require lifelong anticoagulant therapy, a therapeutic dilemma can ensue. Therefore, Reesink and colleagues ${ }^{34}$ proposed that even mild hemoptysis in patients with CTEPH warrants prompt evaluation, and embolization treatment should be offered as the first choice for these patients. Accordingly, in the present study, PTOBPCA was initially performed in patients with CTEPH and mild to severe hemoptysis beginning in January 2007. The patients undergoing BPCA occlusion had a much more uneventful surgical recovery than did those who had not undergone the procedure. Therefore, the procedure was performed in more patients, primarily those with a history of hemoptysis. PTOBPCA continued to be conducive to post-PEA
TABLE 4. Comparison between groups $A$ and $B$ for intubation time, ICU stay, mPAP, PVR, $\mathrm{PaO}_{2}, \mathrm{SaO}_{2}$, and medical expenditure

\begin{tabular}{|c|c|c|c|}
\hline Variable & $\begin{array}{l}\text { Group A } \\
(\mathbf{n}=\mathbf{8 7})\end{array}$ & $\begin{array}{l}\text { Group B } \\
(\mathbf{n}=68)\end{array}$ & $\begin{array}{l}P \text { value } \\
\left(t \text { or } \chi^{2}\right)\end{array}$ \\
\hline Intubation (h) & $71.7 \pm 27.5$ & $39.8 \pm 15.6$ & $.000(8.547)$ \\
\hline ICU stay (d) & $4.8 \pm 2.9$ & $3.5 \pm 2.6$ & $.004(2.897)$ \\
\hline \multicolumn{4}{|l|}{ mPAP $(\mathrm{mm} \mathrm{Hg})$} \\
\hline At $0 \mathrm{~h}$ & $38.6 \pm 10.4$ & $33.2 \pm 9.1$ & $.001(3.386)$ \\
\hline At $72 \mathrm{~h}$ & $35.5 \pm 11.9$ & $28.4 \pm 10.2$ & $.000(3.921)$ \\
\hline \multicolumn{4}{|l|}{ PVR (dynes/s/cm ${ }^{-5}$ ) } \\
\hline At $0 \mathrm{~h}$ & $456.3 \pm 182$ & $362 \pm 176$ & $.002(3.248)$ \\
\hline At $72 \mathrm{~h}$ & $342 \pm 213$ & $256 \pm 143$ & $.005(2.862)$ \\
\hline $\mathrm{PaO}_{2}(\mathrm{~mm} \mathrm{Hg})$ at $72 \mathrm{~h}$ & $88.1 \pm 16.7$ & $105.2 \pm 22.1$ & $.000(5.423)$ \\
\hline $\mathrm{PaO}_{2} / \mathrm{FiO}_{2}$ ratio at $72 \mathrm{~h}$ & $379 \pm 42$ & $428 \pm 36$ & $.000(7.667)$ \\
\hline $\begin{array}{l}\text { Medical expenditure (10 } \\
\text { thousand RMB) }\end{array}$ & $18.6 \pm 3.9$ & $15.5 \pm 3.4$ & $.000(5.191)$ \\
\hline
\end{tabular}

Data presented as mean \pm standard deviation. ICU, Intensive care unit; $m P A P$, mean pulmonary artery pressure; $\mathrm{PVR}$, pulmonary vascular resistance; $\mathrm{PaO}_{2}$, partial pressure of oxygen in arterial blood; $\mathrm{PaO}_{2} / \mathrm{FiO}_{2}$ ratio, ratio of arterial oxygen tension to fraction of inspired oxygen; $O \mathrm{~h}$, immediately postoperatively; $72 \mathrm{~h}, 72 \mathrm{~h}$ postoperatively; $R M B$, renminbi.

recovery. Therefore, the present retrospective study was initiated to document its effect. The analysis has confirmed that PTOBPCA reduces ECMO usage, alleviates REP, and improves early hemodynamics after PEA.

The difference in the preoperative and postoperative OPS between the 2 groups did not reach statistical significance; therefore, the difference in postoperative performance cannot be attributed to the different thromboendarterectomy technique but instead to PTOBPCA. The patients undergoing PTOBPCA were less likely to require ECMO, had decreased intubation times, shorter ICU stays, lower mean pulmonary artery pressures and pulmonary vascular resistance, and higher oxygen saturation and partial pressures of oxygen in arterial blood after PEA (Table 2). Overall, PTOBPCA appears to effectively prevent RPE after PEA and could provide several distinct advantages.

\section{Study Limitations}

The present study had several limitations. This was a retrospective, single-center study performed during a 6 -year period and lacked randomization. Thus, any clear association between the early and late PEA and PTOBPCA outcomes are obscured. To definitively assess the efficacy of PTOBPCA, additional studies of a larger population are needed to confirm the present findings. Overall, the sample size was limited and other risk factors could not be controlled; therefore, the present study results should be considered inconclusive and preliminary. A randomized controlled trial is needed to determine the role of PTOBPCA in preventing RPE.

\section{CONCLUSIONS}

PTOBPCA can alleviate RPE, shorten the ICU stay, decrease the intubation duration, reduce ECMO usage, 
and improve early hemodynamic function after PEA. Should additional clinical investigations confirm that PTOBPCA improves the PEA outcome, wider implementation and a randomized controlled trial of the procedure will be warranted.

\section{References}

1. Corsico AG, D’Aumini AM, Cerveri I, Klersy C, Ansaldo E, Niniano R, et al. Long-term outcome after pulmonary endarterectomy. Am J Respir Crit Care Med. 2008;178:419-24.

2. Thistlethwaite PA, Kaneko K, Madani M, Jamieson SW. Technique and outcomes of pulmonary endarterectomy surgery. Ann Thorac Cardiovasc Surg. 2008; $14: 274-82$.

3. Thomson B, Tsui SS, Dunning J, Goodwin A, Vuylsteke A, Latimer R, et al. Pulmonary endarterectomy is possible and effective without the use of complete circulatory arrest-the UK experience in over 150 patients. Eur J Cardiothorac Surg. 2008;33:157-63.

4. Endrys J, Hayat N, Cherian G. Comparison of bronchopulmonary collaterals and collateral blood flow in patients with chronic thromboembolic and primary pulmonary hypertension. Heart. 1997;78:171-6.

5. Jamieson SW, Kapelanski DP. Pulmonary endarterectomy. Curr Probl Surg. 2000;37:165-252

6. Jamieson SW, Kapelanski DP, Sakakibara N, Manecke GR, Thistlethwaite PA, Kerr KM, et al. Pulmonary endarterectomy: experience and lessons learned in 1,500 cases. Ann Thorac Surg. 2003;76:1457-62.

7. Madani MM, Jamieson SW. Technical advances of pulmonary endarterectomy for chronic thromboembolic pulmonary hypertension. Semin Thorac Cardiovasc Surg. 2006; 18:243-9

8. Jenkins DP, Madani M, Mayer E, Kerr K, Kim N, Klepetko W, et al. Surgical treatment of chronic thromboembolic pulmonary hypertension. Eur Respir J. 2013:41:735-42.

9. Kunihara T, Cerdts J, Groesdonk H, Sata F, Langer F, Tscholl D, et al. Predictors of postoperative outcome after pulmonary endarterectomy from a 14-year experience with 279 patients. Eur J Cardiac Surg. 2011;40:154-61.

10. Kerr KM, Auger WR, Marsh JJ, Comito RM, Fedullo RL, Smits GJ, et al. Selective blockade with CY-1503 may prevent reperfusion lung injury following pulmonary thromboendarterectomy [abstract]. Am J Respir Crit Care Med. 1997; 155:A898.

11. Iversen S. Thoracic research scholarship 1988: pulmonary thromboendarterectomy for chronic thromboembolic pulmonary hypertension at the University of California, San Diego. Thorac Cardiovasc Surg. 1990;38:86-90.

12. Levinson RM, Shure D, Moser KM. Reperfusion pulmonary edema after pulmonary artery thromboendarterectomy. Am Rev Respir Dis. 1986;134: 1241-5.

13. Manecke GR, Kotzur A, Atkins G, Fedullo PF, Auger WR, Kapelanski DP, et al. Massive hemorrhage after pulmonary endarterectomy. Anesth Analg. 2004;99: $672-5$.

14. Berman M, Tsui S, Vuylsteke A, Snell A, Colah S, Latimer R, et al. Successful extracorporeal membrane oxygenation support after pulmonary thromboendarterectomy. Ann Thorac Surg. 2008;86:1261-7.

15. Gan HL. Pulmonary Embolism and Pulmonary Thromboendarterectomy. New York: Nova Science Publishers; 2011.

16. Inami T, Kataoka M, Shimura N, Ishiguro H, Yanagisawa R, Taguchi H, et al. Pulmonary edema predictive scoring index (PEPSI), a new index to predict risk of reperfusion pulmonary edema and improvement of hemodynamics in percutaneous transluminal pulmonary angioplasty. JACC Cardiovasc Interv. 2013;6:725-36.

17. Daily PO, Dembitsky WR, Peterson KL. Modifications of techniques and early results of pulmonary thromboendarterectomy for chronic pulmonary embolism. J Thorac Cardiovasc Surg. 1987;93:221-3.

18. Khimenko PL, Barnard JW, Moore TM, Wilson PS, Ballard ST, Taylor AE Vascular permeability and epithelial transport effects on lung edema formation in ischemia and reperfusion. J Appl Physiol. 1994;77:1116-21.

19. Horgan MJ, Ge M, Gu J, Rothlein R, Malik AB. Role of ICAM-1 in neutrophilmediated lung vascular injury after occlusion and reperfusion. Am J Physiol. 1991;261:H1578-84.

20. Fadel E, Riou JY, Mazmanian M, Brenot P, Dulmet E, Detruit H, et al. Pulmonary thromboendarterectomy for chronic thromboembolic obstruction of the pulmonary artery in piglets. J Thorac Cardiovasc Surg. 1999;117:787-93.

21. Moser KM, Auger WR, Fedullo SW, Jamieson SD. Chronic thromboembolic pulmonary hypertension: clinical picture and surgical treatment. Eur Respir J. 1992; 5:334-42.

22. Fischer S, Maclean AA, Liu M, Cardella JA, Slutsky AS, Suga M, et al. Dynamic changes in apoptotic and necrotic cell death correlate with severity of ischemiareperfusion injury in lung transplantation. Am J Respir Crit Care Med. 2000;162: 1932-9.

23. Sage E, Mercier O, Van den Eyden F, de Perrot M, Barlier-Mur AM, Darteville P, et al. Endothelial cell apoptosis in chronically obstructed and reperfused pulmonary artery. Respir Res. 2008;9:19-29.

24. Chitwood WR, Sabistou DC, Wechsler AS. Surgical treatment of chronic unresolved pulmonary embolism. Clin Chest Med. 1984;5:507-36.

25. Thistlethwaite PA, Mo M, Madani MM, Deutsch R, Blanchard D, Kapelanski DP, et al. Operative classification of thromboembolic disease determines outcome after pulmonary endarterectomy. J Thorac Cardiovasc Surg. 2002;124:1203-11.

26. Madani MM, Jamieson SW. An insider's guide to pulmonary thromboendarterectomy: proven techniques to achieve optimal results. Adv Pulmonary Hypertension. 2003;2:13-20.

27. Thistlethwaite PA, Madani MM, Kemp AD, Hartley M, Auger WR, Jamieson SW. Venovenous extracorporeal life support after pulmonary endarterectomy: indications, techniques and outcomes. Ann Thorac Surg. 2006;82:2139-46.

28. Mares P, Gilbert TB, Tschernko EM, Hiesmayr M, Muhm M, Herneth A, et al Pulmonary artery thromboendarterectomy: a comparison of two different postoperative treatment strategies. Anesth Analg. 2000;90:267-73.

29. Manecke GR, Wilson WC, Auger WR, Jamieson SW. Chronic thromboembolic pulmonary hypertension and pulmonary thromboendarterectomy. Semin Cardiothorac Vasc Anesth. 2005;9:189-204.

30. Imanaka H, Miyano H, Takeuchi M, Kumon K, Ando M. Effects of nitric oxide inhalation after pulmonary thrombo-endarterectomy for chronic pulmonary thromboembolism. Chest. 2000;118:39-46.

31. Kramm T, Eberle B, Krummenauer F, Guth S, Oelert H, Mayer E. Inhaled iloprost in patients with chronic thromboembolic pulmonary hypertension: effects before and after pulmonary thromboendarterectomy. Ann Thorac Surg. 2003; 76:711-8.

32. Wagenwoort CA, Denolin H. Pulmonary Circulation: Advances and Controversies. Amsterdam: Elsevier; 1989

33. Fedullo PF, Auger WR, Dembitsky WP. Postoperative management of the patien undergoing pulmonary thromboendarterectomy. Semin Thorac Cardiovasc Surg. 1999;11:172-8.

34. Reesink HJ, van Delden OM, Kloek JJ, Jansen HM, Reekers JA, Bresser P. Embolization for hemoptysis in chronic thromboembolic pulmonary hypertension: report of two cases and a review of the literature. Cardiovasc Intervent Radiol. 2007:30:136-9. 